\title{
Mathematical Modeling and Optimization of Schemes of Major Agronomic Factors for Hybrid Rice 'Yongyou 17'
}

\author{
Liu Weiming ${ }^{1}$ and Bao Zuda ${ }^{2}$ \\ ${ }^{1}$ Taizhou Vocational College of Science \& Technology, Zhejiang, Taizhou 318020 \\ ${ }^{2}$ Seed Management Station, JiaoJiang, TaiZhou, ZheJiang, Taizhou 318000 \\ 15157622288@139.com
}

\begin{abstract}
In this study, the computer aided modeling and optimization was used to select agronomic scheme of high yield and high net profit for a single-season late rice hybrid 'Yongyou 17'. A field experiment with three agronomic factors including seedling age, planting density, pure $\mathrm{N}$ fertilizer rate were performed and the data were used to construct regression models using yield and net profit as the objective variables. Simulation of those models produced the optimum schemes consisting of seedling age, planting density and pure $\mathrm{N}$ fertilizer rate to achieve the highest yield and net profit.
\end{abstract}

Keywords: hybrid rice, agronomic scheme, mathematical model, model optimization, nitrogen fertilizer, seedling stage, planting density, yield, net profit.

\section{$1 \quad$ Introduction}

Nowadays, the optimal experimental design used has been widely used inin agricultural studied [1-4]. Rotational combination design, the secondary saturated D-optimal design, and simplex lattice design were all applied in the studies for high-yield cultivation techniques in rice, sweet potatoes, corn, soybean, turmeric (Dioscorea) by this research group [5-10]. In this study, rotational combination design was used to conduct field trials for establishing a mathematical model for optimal management of the single-season rice hybrid 'Yongyou 17'.

'Yongyou 17' is a three-line Indica-Japonica hybrid cultivar bred by the Crop Institute of Agricultural Academy of Zhejiang Province and Ningbao Seed Company, Ltd. The cultivar was registered in Zhejiang Province in 2012 (Zhe Registrar Rice 2012018). The cultivar has good stem strength; it is highly resistant to lodging. It has a medium growth period with nice pigment change during the late growth stage. The big panicles with dense grains produce high yield. The objective of this study was to determine the effects of major agronomic traits on yield and net profit of 'Yongyou17'.

\section{Materials and Methods}

The field experiment was set up using the seedling age $\left(x_{1}\right.$, days), planting density $\left(x_{2}\right.$, cluster/hm $\left.{ }^{2}\right)$, pure $\mathrm{N}$ fertilizer rate $\left(x_{3}, \mathrm{~kg} / \mathrm{hm}^{2}\right)$ as the decision variables in a

D. Li and Y. Chen (Eds.): CCTA 2013, Part I, IFIP AICT 419, pp. 464 469, 2014.

(C) IFIP International Federation for Information Processing 2014 
tertiary quadratic general rotary design [11]. Table 1 contains the three decision variables, the treatment levels and the corresponding linear code. The yield and net profit were used as the objective variables.

Table 1. Decision variables and the treatment levels

\begin{tabular}{cccc}
\hline Linear code & $x_{1}$ & $x_{2}$ & $x_{3}$ \\
\hline+1 & 30 & 202500 & 201.15 \\
-1 & 18 & 127500 & 51.15 \\
0 & 24 & 165000 & 126.15 \\
+1.682 & 34 & 228075 & 252.30 \\
-1.682 & 14 & 101925 & 0 \\
\hline
\end{tabular}

Seedling age was controlled by sowing seeds at different dates (Table 1). Seeds sowed on May 26th, 30th, June 4th, 10th and 14th produced seedlings of 34, 30, 24, 18 and 14 days, respectively, at the transplanting date on June $28^{\text {th }}$. Single plant was planted per hole.

The size of each plot was $16 \mathrm{~m}^{2}(3.2 \mathrm{~m} \times 5 \mathrm{~m})$. To prevent fertilizer from leaching into adjacent plots, the between plot area was covered with plastic film. In each plot, 450 $\mathrm{kg} / \mathrm{hm}^{2}$ of calcium phosphate was applied as base fertilizer. $\mathrm{KCl}\left(300 \mathrm{~kg} / \mathrm{hm}^{2}\right)$ was used in three applications at a ratio of 1:2:2, as base fertilizer, at 15 days post-transplanting, and panicle fertilizer. Pure $\mathrm{N}$ fertilizer rate was $252.30,201.15,126.15,51.15 \mathrm{~kg} / \mathrm{hm}^{2}$. Nitrogen fertilizer was applied five times in a ratio of $4 ; 2 ; 2 ; 1 ; 1$, as base fertilizer, 7 and 15 days after transplanting, flowering fertilizer, and seed set fertilizer. The field experiment was performed in 2012, in Shujiang district, Taizhou, Zhejiang. Except for the treatments, the experimental field was managed consistently.

\section{$3 \quad$ Results and Analysis}

According to the quadratic regression orthogonal rotation design principles, a regression mathematical model was obtained as follows:

$$
\hat{y}=b_{0}+\sum_{i=1}^{3} b_{i} x_{i}+\sum_{i<j} b_{i j} x_{i} x_{j}+\sum_{i=1}^{3} b_{i i} x_{i}^{2}+\sigma
$$

In which, (the Chinese words in the following formula should be changed to English word or letters)

$$
\sigma=\sqrt{S S_{\text {剩 }} / f_{\text {剩 }}}
$$

Based on the structureof thematrix and theobtained yield andnet output ofYongyou17, quadraticregression analyseswere carried outfocusing on the yield and profit. 


\subsection{Yield Result Analysis}

Using the tertiary quadratic general rotary regression analysis, models for the three agronomic traits and yield were constructed as follows:

$$
\hat{y}_{1}=12808.65-92.7 x_{1}+490.65 x_{2}+1247.55 x_{3}-56.25 x_{1}^{2}-415.2 x_{2}^{2}-688.35 x_{3}^{2}-97
$$

$.35 x_{1} x_{2}+333.6 x_{1} x_{3}-13.35 x_{2} x_{3}$

$$
\left(-1.682 \leq x_{i} \leq 1.682, \quad i=1,2,3\right)
$$

In the model, $x_{2}, x_{3}, x_{2}^{2}$ and $x_{3}^{2}$ are at the extremely significant level, and $x_{1} x_{3}$ are at a significant level. The rest of variables are not significant $(\alpha=0.25)$. To increase accuracy level, all the non-significant variables were excluded from the models. Then the regression model was rewritten as:

$$
\begin{array}{r}
\hat{y}_{1}=12808.65+490.65 x_{2}+1247.55 x_{3}-415.2 x_{2}^{2}-688.35 x_{3}^{2}+333.6 x_{1} x_{3} \\
\left(-1.682 \leq x_{i} \leq 1.682, \quad i=1,2,3\right)
\end{array}
$$

In this regression models, all the variables are significant, and the lack-of-fit sum of squares is not significant. These models should be very effective for simulation experiment.

Test of significance identified yield is mainly affected by planting density and pure $\mathrm{N}$ fertilizer rate, and seedling age has a smaller effect. When compared for interaction effect $\left(x_{1} x_{3}\right)$, it was found that the lower nitrogen fertilizer rate should be combined with younger seedlings, and higher fertilizer rate with older seedlings. In general, higher $\mathrm{N}$ fertilizer rate was correlated with higher yield. When seedling age and nitrogen fertilizer rate were set around treatment level 1, the yield was at the highest level.

\subsection{Profit Result Analysis}

In this study, rice, seedling, urea, $\mathrm{KCl}$, and calcium phosphate were priced at 2.80 yuan $/ \mathrm{kg}, 52$ yuan $/ 10,000$ seedlings, 2.50 yuan $/ \mathrm{kg}, 3.60$ yuan $/ \mathrm{kg}$ and 0.90 yuan $/ \mathrm{kg}$, respectively. When estimating the investment, only the cost of materials and supplies were included. After converting the net profit per plot into profit per hectare, a ternary quadratic general rotary regression model was constructed. After exclusion of variables that are not significant $(\alpha=0.25)$, the regression model for net profit is described as follows:

$$
\begin{gathered}
\hat{y}_{2}=32565.60+1178.85 x_{2}+3085.50 x_{3}-1162.65 x_{2}^{2}-1927.35 x_{3}^{2}+934.05 x_{1} x_{3} \\
\left(-1.682 \leq x_{i} \leq 1.682, \quad i=1,2,3\right)
\end{gathered}
$$

Test of significance showed that, same as in the yield model, $x_{2}, x_{3}, x_{2}^{2}, x_{3}^{2}$ are extremely significant, and $x_{1} x_{3}$ is at a significant level. The overall regression model is extremely significant. The relationship between the three agronomic factors and net profit is approximately the same as that in the yield model. Planting density and pure $\mathrm{N}$ fertilizer rate are the major factors influencing profit, while the effect from seedling 
age is relatively small. The interaction effect of $x_{1} x_{3}$ on net profit is also similar to that on yield. Lower nitrogen fertilizer rate combined with younger seedlings, and higher fertilizer rate with older seedlings should yield a higher net profit. The highest net profit was achieved when the seedling age and nitrogen rate were both set at around treatment level 1.

These results indicate that the three agronomic factors have a consistent effect on yield or net profit. Therefore agronomic schemes aimed at increasing yield also can produce high net profit. Then the optimum agronomic schemes for high yield and high profit were selected using computer simulation of the mathematical models described above.

\section{$4 \quad$ Model Optimization}

\subsection{Optimization of the Agronomic Schemes for High Yield}

The high yield agronomic schemes were selected using the yield regression model and selecting $\left(-1.682 \leq x_{i} \leq 1.682\right)$ as the region for constrain [12, 13]. Twenty-one schemes were found to produce a yield above $12900 \mathrm{~kg} / \mathrm{hm}^{2}$ (Table 2). At the $95 \%$ confidence level, the value of $x_{1}, \mathrm{x}_{2}, x_{3}$ each was 0.456-1.206 (26-31 days), 0.282-0.995 (175575-202305 clusters $\left./ \mathrm{hm}^{2}\right)$ and $1.148-1.437\left(212.25-233.85 \mathrm{~kg} / \mathrm{hm}^{2}\right)$.

Table 2. Computer model using increasing yield as the objective variable

\begin{tabular}{ccccccc}
\hline Level & $x_{1}$ & Frequency & $x_{2}$ & Frequency & $x_{3}$ & Frequency \\
\hline-1.682 & 0 & 0.000 & 0 & 0.000 & 0 & 0.000 \\
-1.000 & 2 & 0.095 & 2 & 0.095 & 0 & 0.000 \\
0.000 & 5 & 0.238 & 7 & 0.333 & 0 & 0.000 \\
1.000 & 6 & 0.286 & 7 & 0.333 & 12 & 0.571 \\
1.682 & 8 & 0.381 & 5 & 0.239 & 9 & 0.429 \\
\hline
\end{tabular}

\subsection{Model Optimization for High Net Profit}

The high profit agronomic schemes were selected by simulating net profit regression model within the same constraint region as for yield. Sixteen schemes were found to produce a net profit exceeding $32700 \mathrm{yuan} / \mathrm{hm}^{2}$ (Table 3 ). The value for $x_{1}, x_{2}, x_{3}$ each (at 95\% confidence level) was 0.479-1.368 (27-32 days), 0.257-0.999 $\left(174638-202463\right.$ clusters $\left./ \mathrm{hm}^{2}\right)$ and $1.058-1.368\left(205.5-228.75 \mathrm{~kg} / \mathrm{hm}^{2}\right)$. It can be seen that the similar values were selected for the three agronomic factors in the net profit schemes and those aimed at high yield. 
Table 3. Computer modeling aimed at increasing the net profit

\begin{tabular}{ccccccc}
\hline Level & $x_{1}$ & Frequency & $x_{2}$ & Frequency & $x_{3}$ & Frequency \\
\hline-1.682 & 0 & 0.000 & 0 & 0.000 & 0 & 0.000 \\
-1.000 & 2 & 0.125 & 1 & 0.063 & 0 & 0.000 \\
0.000 & 2 & 0.125 & 6 & 0.375 & 0 & 0.000 \\
1.000 & 5 & 0.313 & 6 & 0.375 & 11 & 0.688 \\
1.682 & 7 & 0.437 & 3 & 0.187 & 5 & 0.312 \\
\hline
\end{tabular}

\section{Conclusions}

In this study, regression models were constructed to simulate the relationship between three agronomic factors (seedling age, planting density, pure $\mathrm{N}$ fertilizer rate) and the yield and net profit of single season hybrid rice 'Yongyou 17'. Model analysis indicates that yield and net profit have similar responses to the three agronomic factors. Among the three agronomic factors, planting density and pure $\mathrm{N}$ fertilizer rate have bigger effects whereas that from seedling age is relatively small. Production schemes were constructed using simulation of mathematical models integrating data from a field experiment. Under the production conditions used in this study, for 'Yongyou 17' to achieve high yield and high profit, the optimum scheme consists of the following conditions: seedling age of 26-30 days, planting density of $165000-180000 \mathrm{cluster} / \mathrm{hm}^{2}$, pure $\mathrm{N}$ fertilizer rate of $210-225 \mathrm{~kg} / \mathrm{hm}^{2}$.

\section{References}

1. Chen, Z.L., Cao, W., Tang, F.D., Huang, L.R., Li, L.D., Ai, J.: Effects of water and fertilizer coupling on seedling biomass of Lespedeza bicolor in sandy land of northwestern Liaoning province. Journal of Northeast Forestry University 39(1), 34-47 (2011)

2. Ruan, P.J., Ma, J., Mei, Y., Yang, Y.P.: Effect of different density and $\mathrm{N}$-application rate on maize quality. Chinese Agricultural Science Bulletin 20(6), 147-149 (2004)

3. Gao, J., Zhang, Y.C.: Application of D-saturation optimum design in culture medium screening for micropropagation of virus-free tube potato. Journal of Qinghai University (Nature Science) 26(3), 24-26 (2008)

4. Liu, Y., Chi, D.Z., Ma, X.G.: Multiplication of subculture for Faba Bean (Vicia faba L.). Journal of Qinghai University (Nature Science) 26(5), 59-61 (2008)

5. Liu, W.M., Ye, A.M.: Study on optimization combination for intercropping spring corn with spring soybean. Acta Agriculturae Zhejiangensis 16(3), 131-135 (2004)

6. Liu, W.M., Wang, R.Z.: Study on fertiilizer application techniques of annual Dioscoreae zingiberensis. Journal of Chinese Medicinal Materials 29(4), 313-315 (2006)

7. Liu, W.M., Xu, J.: Research on the transplanting density and nitrogen application for Zhongzheyou 1 planted as single cropping late rice. Hybrid Rice 21(5), 50-53 (2006)

8. Liu, W.M., Yan, B.L., Zhao, Y.F., Wu, L.H.: Effect of planting density and rates of nitrogen and potassium fertilizers on yield and economic efficiency of sweet potato (cv. Zheshu 13). Acta Agriculturae Zhejiangensis 19(1), 55-59 (2007) 
9. Liu, W.M., Wu, L.H.: Optimized test on comprehensive agronomic measures of Zheshu 13. Seed 26(4), 73-75 (2007)

10. Liu, W.M., Xi, T.W., Zhu, D.H., Zhu, S.L.: Comprehensive agronomic optimization for Zheqiu soybean 3. Bulletin of Science and Technology 23(3), 382-385 (2007)

11. Yang, D.: Experimental Design and Statistical Analysis, pp. 227-255. China Agriculture Press, Beijing (2002)

12. Liu, W.M., Yu, Z.Y.: Application of rotary regression experimental design in agronomy optimization experiment. Applied Probability and Statistics 3(3), 274-275 (1987)

13. Liu, W.M.: Application of regression design in the study of intercropping system of crops. Statistics and Management 25(5), 1-5 (2005) 